\title{
Breach of employer obligation and employee well-being during COVID-19 unlock phase
}

\author{
Anushree Karani $^{\mathrm{a}, \mathrm{b}, *}$, Revati Deshpande ${ }^{\mathrm{c}}$, Mitesh Jayswal ${ }^{\mathrm{b}}$ and Payal Trivedi ${ }^{\mathrm{d}}$ \\ ${ }^{a}$ Indian Council for Social Science Research affiliated to Sardar Patel University, Vallabh Vidyanagar, \\ Gujarat, India \\ ${ }^{\mathrm{b}}$ Department of Business Management, Sardar Patel University, Vallabh Vidyanagar, \\ Gujarat, India \\ ${ }^{\mathrm{c}}$ Independent Researcher, Kadi, Gujarat, India \\ ${ }^{\mathrm{d}}$ Jagdish Sheth School of Management, Electronic City Phase I, Bengaluru, Karnataka, India
}

Received 22 March 2021

Accepted 17 June 2021

\begin{abstract}
. psychological distress and well-being during COVID-19 unlock phase. faction) of the employees. satisfaction

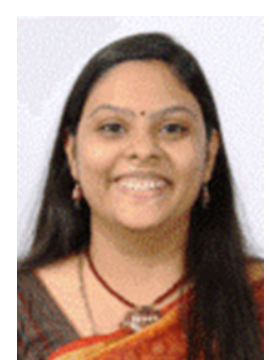

Dr. Anushree Karani is currently pursuing her Post-doctoral Fellowship at Sardar Patel University, Vallabh-Vidyanagar. She is offered fellowship by ICSSR, Ministry of Human Resource Development. Her academic areas of interest are Human Resource Management, Organization Behaviour and Strategic Human Resource Management. Dr. Karani has contributed to various journals,
\end{abstract}

BACKGROUND: The current study explored the relationship between breach of employer obligations, family-work conflict,

OBJECTIVE: The study aimed to understand the breach of how the breach of employer obligation lead to decreased well-being through the family-work conflict and psychological distress during the COVID-19 unlock phase.

METHODS: The data was collected through structured questionnaire via Google doc from 397 employees across the industries. Snowball sampling was adopted, and SmartPLS 3.0 was used for the structural equation model.

RESULTS: Breach of employer obligations are positively affecting family-work conflict. Further, family-work conflict increases the psychological distress, and psychological distress decreases the well-being (life satisfaction and family satis-

CONCLUSION: The novel contribution of the study is integrating SET, COR and SIP theory during the pandemic situation. The results highlighted meticulous empirical evidence which answers the question of how the unmet expectations cause a detrimental effect on the employees as well as the organizations in this COVID-19 pandemic situation.

Keywords: Breach of employer obligations, family-work conflict, psychological distress, well-being, life satisfaction, family

${ }^{*}$ Corresponding author: Dr. Anushree Karani, Indian Council for Social Science Research affiliated to Sardar Patel University; G.H. Patel Postgraduate Department of Business Management, Sardar Patel University, Vallabh Vidyanagar, 388120, Gujarat, India. Tel.: +919033785458; E-mail: anushree karani@gmail.com., ORCID ID: 0000-0003-2590-9424 book chapters and conferences of national and international repute. Dr. Karani is serving as a full time faculty member at Shri Jairambhai Patel Institute of Business Management and Computer Applications, Gandhinagar. Currently Dr. Karani is on sabbatical for two years to pursue her Post-doctoral fellowship. 


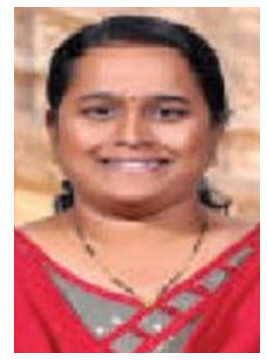

Dr. Revati Deshpande is an independent researcher. Dr. Deshpande is having more than seventeen years of work experience of academics and industry. Her academic areas of interest are Human Resource Management, Organization Behaviour, Strategic Human Resource Management, Work Life Balance and Stress Management. Dr. Deshpande has contributed to various journals and conferences of national and international repute. Currently Dr. Deshpande is serving as a visiting Gandhinagar and Ahmedabad. faculty at some of the b-schools of

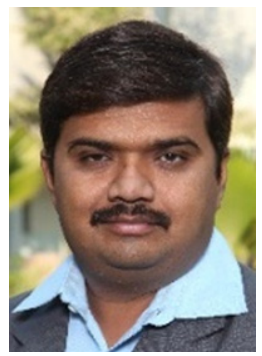

Dr. Mitesh Jayswal is currently working as a professor at G.H. Patel Postgraduate Department of Business Management at Sardar Patel University. He is having seventeen years of work experience of academics and industry. He has authored three books and presented research papers at international and national level conferences. He was selected for the Research grant of Rs. 50000/- for doctorate work by Insurance Institute of India, Bombay. In this context, also invited to presented research work at $58^{\text {th }}$ annual conference, where felicitated by Mr. T S Vijayan, Chairman of IRDA. The project is completed. He has published research papers in Scopus, ABDC and UGC listed journals. He has received Sardar Patel Research Award - 2017 by Sardar Patel University, Vallabh Vidyanagar.

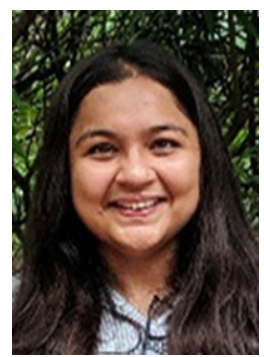

Prof. Payal Trivedi is a fellow from MICA, Ahmedabad. Previously she worked as an Assistant Professor (Marketing) at Pune Institute of Business Management, Pune and had also worked as an Academic Associate (Marketing) at Indian Institute of Management, Ahmedabad (IIM-A). Apart from the academic experience, she also had a stint at the corporate working as an inbound sales executive with Jindal RHM Interactive Private Ltd., Ahmedabad. Her research interests include customer focused business strategies; sustainable marketing; digital marketing, and psychological contract. She has published and presented research works in national and international symposiums.

\section{Introduction}

In recent times, research in the domain of Psychological Contract (PC) has gained much attention from the academia and industry because of its potential in understanding the employer-employee relationship in a better way [1]. However, the concept of PC is not new; the roots of this concept can be traced back to 1960s. [2] coined the term 'psychological contract', and he has taken PC as an unspoken agreement between the employees' group and their foremen. This relationship could be advanced to such a degree that the employees share higher productivity and lower complaints in return for reasonable salaries and job security [3]. However, the contemporary concept of $\mathrm{PC}$ has been reconceptualized by [4] where PC is seen as one's perception concerning the terms and conditions of mutual agreement between the two parties or individuals. In the new normal era, the expectations of employees have changed as the COVID-19 pandemic situation is effecting negatively on our economy and on the world of work where it is proving to be even worse than the 2008-09 subprime crisis [5]. Among the plethora of health risks that the coronavirus has exposed us to, our career is in a very vulnerable state. The rate of unemployment has been increasing. In India, too, many people across industries were subjected to salary cuts ranging anywhere from $5 \%$ to $60 \%$ and more [6], and a few unfortunate ones even lost their jobs. The unlock phase that has begun, the employers are attempting arduous to normalize with safety. Currently, the mud has emerged to settle at work. After this rapid change in the workplace, there was more disruption in the day to day life aspects of employees leading to the feeling of stress, tiredness, frustration, disconnected and de-motivated among the employees [7].

There is a possibility that employer is unable to fulfill their employees' expectations and hence employee perceives it as a breach of obligations which is unavoidable in today's era [8]. Breach of employer obligations results in the feeling of disappointment, distress, anger, outrage, bitterness, and resentment among employees which results in a perception of betrayal among them. Individuals react differently to their experiencing stress and their reaction towards organizations [9-11]. In an individual's life, work and family both are the most important spheres [12]. Nevertheless, the role expectations from work and family are not always synchronized, and this creates an imbalance between work and family life [4]. When the employer is unable to fulfill the employee's demand, it also creates an imbalance in his/her work and family life [13]. Additionally, breach of any kind resulting in family-work conflict irrespective of family-friendly policy exists in the organization [14] Any conflict within the organization lead to distress, and the feeling of distress can lead to health-related issues, and this is a very costly affair for the organization [15]. Therefore wellbeing at work comes into the picture. Therefore the present study has been built on social exchange 


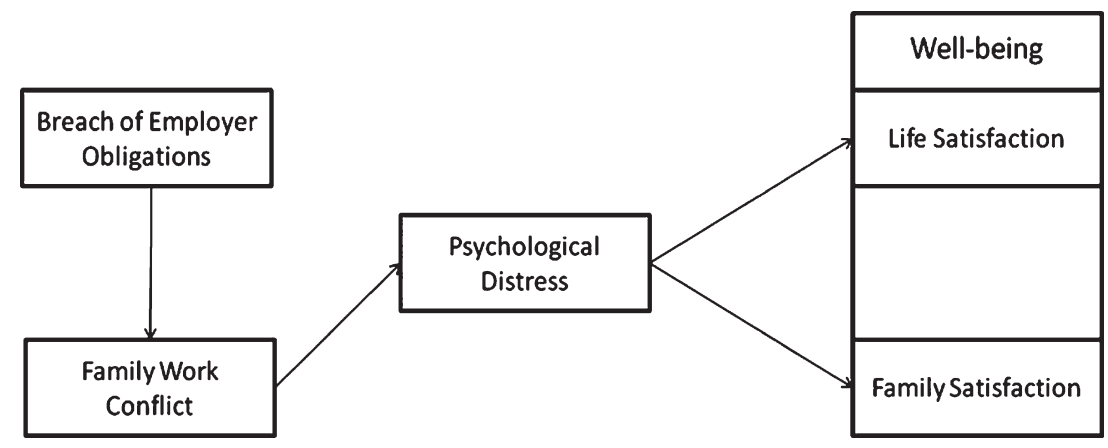

Fig. 1. Proposed Model.

theory (SET) [16], conservation of resource theory (COR) [13] and social information processing (SIP) theory [17]. The study highlighted that the key pathway through which the breach of employer obligations positively impacts family-work conflict and family-work conflict positively impacts psychological distress. Further, psychological distress negatively impacted on the well-being (i.e. life and family satisfaction) of the employees.

\section{Theory and hypothesis development}

The current study has integrated the SET [16], COR [13] and SIP [17] theories. PC is rooted in SET, and it suggests that there is a two-way relationship, if there is something offered then there is a quiet pledge to return it equally $[18,19]$. Based on SET, we argue that employees have certain expectations from their employer. COR theory argued that when employees are not provided appropriate resources, it leads to stress [20,21] and also have an adverse impact on well-being [22]. Based on COR theory, we predict that family-work conflict leads to psychological distress and further have a negative impact on the well-being of the employees. Based on SIP theory, it was argued that modes of communication influence the attitude and behaviour of the employee. [13] suggested to use SIP theory in an Asian context to understand how employees interpret information influencing PC, which led to job outcomes.

\subsection{Breach of employer obligations and family-work conflict}

PC was first conceptualized by [23] as "an individual's belief regarding the terms and conditions of a reciprocal exchange agreement between the focal person and another party". Employees perceive a breach of PC when the organizations do not meet or fulfill these obligations [13, 23, 24]. [25] explained the breach of employer obligations perceived as the loss of resources. When the employees feel that the organization do not provide support and resources as promised and the demand for work is high, then the experience of the breach can harm the attitude and behaviour [26]. Breach of employer obligations in the current situation is very critical to understand. The past studies of psychological contract breach are related to intension to leave the organization [27-29]. However, in the current situation, this response to the breach of employer obligations is not likely to occur. Because currently, employees would like to engage in their jobs to remain employed. Hence, when an employee cannot leave the organization, it leads to frustration, and it impacts their family-work conflict. Family-work conflict occurs when family life is interfering work life of an individual [30]. There is a dearth of literature on relationship between breach of employer obligation i.e. PC and family-work conflict. However, [105] explained that breach of psychological contract can impacts the work-family interface. $\mathrm{PC}$ is essential to understand the breakdown of family-work conflict in work-related expectations [31]. Therefore, we propose that;

H1: Breach of employer obligations are positively related to family-work conflict

\subsection{Family-work conflict and psychological distress}

The family-work interface is having a high association with the psychological strain [32], poor physical well-being [33], higher fatigue [34] and depression and fretfulness [35]. Psychological stress can 
be defined as, "an umbrella term that encompasses stress, burnout, depression, anxiety and other related mental health problems" [33, p. 995]. At workplace psychological distress is originated from unhappiness, depression, anxiety, workload, the primary dimension [37] and also [38] reported as mental illness generation from occupational stress. It was found that psychological stress is a result of work-family interface, job pressure work experiences among the construction professionals of Australia. In past studies, the family-work conflict has been considered as predictors of burnout and stress [39, 40]. Previous studies have mentioned that family-work conflict is having a strong association with psychological distress [42-44, 102-104]. Hence, we propose that;

H2: Family-work conflict is positively related to psychological distress

\subsection{Psychological distress and well-being}

According to [43], the core concept of well-being is "the subjective experience of feeling good and/or feeling authentic and meaningful in one's life, and it is conceptually different from perception, motivation and actions". Psychological distress is having a substantial impact on the well-being of an individual $[44,45]$. Majority of the past studies have focused on the multi-dimensional construct of well-being [66, 67]. In the current study, well-being is understood as life and family satisfaction. Life satisfaction can be understood as a cognitive appraisal of the overall degree of satisfaction an individual has with his/her life [46]. [47] argued that due to fear of COVID19 increased psychological distress, and it results in decreased life satisfaction of the employees. Family satisfaction reflects the well-being of a person in the family domain [48]. It is defined as the "degree to which one is generally satisfied with one's family of origin and the constituent relationships embedded therein" [38, p. 72] and conceptualized as a result of stress on the family domain. Incumbents often accuse that work ambiguity/overload, inflexible work and lack of job support will undermine their family satisfaction $[50,51]$. Past studies confirmed the negative relationship between stress and well-being [52-56]. In this lockdown period during COVID-19 pandemic situation results in stress, and it negatively related to the life and family of employees. Social distancing has made it compulsory to work via technology. Moreover, workload and demand can be increased because of information technology [57]. It increases the chances of surveillance and thus increases stress [58]. Past studies have also argued that psychological distress can have a negative impact on life satisfaction $[59,60]$ and family satisfaction $[61,62]$ of the employee. Thus, we propose that;

H3: Psychological distress is negatively related to well-being

H3a: Psychological distress is negatively related to life satisfaction

$\mathrm{H} 3 \mathrm{~b}$ : Psychological distress is negatively related to family satisfaction

\section{Methodology}

\subsection{Sample and procedure}

Our study surveyed service sector employees who belong to information technology and information technology enabled services (IT/ITes), financial services and education sector in India. The respondents of the study are not from same hierarchal level as well not of similar demographic profile. We have followed a quantitative approach and descriptive research design. We have adopted snowball sampling. Further, the cost-effective nature of forwarding the survey link is preferred due to non-funding nature of this study. This helped the researcher to reach to the targeted large sample size. The duration of data collection was from June 2020 to December 2020. Due to pandemic, it was not feasible to reach the respondents in person. Thus, the respondents were contacted through an online survey via Google Docs. Out of 600 questionnaires, we received 435 filled in questionnaires out of which 397 usable sample responses were identified. Remaining responses were rejected due to incomplete or missing data. Demographic profile of the respondents has been presented in Table 1 .

\subsection{Measures}

For the purpose of this study, we utilized multi-item measures that have been used in previous studies. All the variables measured using 5 point likert scale, where Strongly Disagree [1] to Strongly Agree [5], Extremely Dissatisfied [1] To Extremely Satisfied [5]. As each of the variables is subjective (e.g., One individual sees psychological contract is fulfilled and other individual feel that it is not fulfilled), the model is conceptualized and analyzed at the individual level. 
Table 1

Sample Characteristics

\begin{tabular}{llcc}
\hline Demographic & Criteria & Frequency & Percentage \\
\hline Monthly Income & $<25000$ & 121 & 30.47 \\
& $25000-50000$ & 164 & 41.3 \\
& $>50000$ & 112 & 28.21 \\
Marital status & Unmarried & 128 & 32.24 \\
& Married & 269 & 67.75 \\
Age & $<31$ & 217 & 54.65 \\
& $31-50$ & 153 & 38.53 \\
\multirow{3}{*}{ Qualification } & Graduation & 27 & 6.8 \\
& Post graduation & 145 & 59.69 \\
\multirow{4}{*}{ Gender } & Others & 15 & 36.52 \\
& Male & 304 & 76.57 \\
& Female & 93 & 23.42 \\
\hline
\end{tabular}

\subsubsection{Breach of employer's obligations}

We assessed employee perceptions of breach of employer obligations using the five-item scale developed by [63]. An example item is "Almost all the promises made by my employer during recruitment have been kept so far" (reverse scored).

\subsubsection{Family-work conflict}

Family-work conflict was measured using the fiveitem scale of [64]. A 5-point Likert scale is used to assess the underlying dimensions of family-work conflict. The sample item includes "The demands of my work interfere with my home and family life".

\subsubsection{Psychological distress}

Psychological distress was measured using the Center for Epidemiological Studies' Depression Scale. Developed by the National Institute on Mental Health [65], the Center for Epidemiological Studies' Depression Scale was designed to measure depressive symptoms in the general population. The sample item includes, "I felt depressed and fearful".

\subsubsection{Well-being}

Majority of the past studies have focused on the multi-dimensional construct of well-being [66, 67]. For the purpose of the current study family satisfaction and life satisfaction were found the most suitable constructs.

3.2.4.1. Family satisfaction: Family satisfaction was measured using a modified version of the 10 item general family satisfaction scale developed by [49]. The sample item includes, "I am happy with my family just the way it is."

3.2.4.2. Life satisfaction: Life satisfaction was measured using a five-item satisfaction with life scale developed by [68]. The sample item includes, "I am satisfied with my life."

\subsection{Control variables}

To eliminate the relationship between independent variables, dependent variables and mediator in this study [69], a number of variables were controlled: Age (measured in years), level of education ( 1 = graduate, 2 = post-graduate, $3=$ others $)$, gender $(1=$ male, $2=$ female $)$ marital status $(1=$ single, $2=$ married, $3=$ widow/divorcee), monthly income (measured in Indian rupees), number of dependents (measured in numbers e.g. one, two...), number of children (measured in numbers e.g. one, two... ) such demographic variables were found to correlate with well-being and psychological distress and hence they were controlled.

\section{Data analysis}

\subsection{Reliability and validity}

Reliability was assessed using Cronbach's alpha. Table 2 depicts that all the variables under study demonstrate values above 0.7 , and hence it is admissible [70]. We examined the convergent and discriminant validity. Bootstrapping was done to estimate the outer loadings and level of significance, and it was found that all the outer loadings were more than 0.6 except (PD1, PD2, PD4, LS4, LS5, FS4, FS5, FS7, FS8) and significant at $p<0.001$. As per [71], the values of AVE should be more than 0.5 , which explains that beyond 50 per cent of the variance of respective constructs as compared with the errors explained. Discriminant validity can be checked using the Forner-Larcker Criterion [71]. According to the Forner-Larcker measure, 'the AVE of each construct should be higher than the construct's highest squared correlation with any other latent construct', and in cross-loadings' represented in Table 2. Based on the diagonal elements $\left({ }^{\mathrm{a}}\right)$, discriminant validity is established.

\subsection{Multicollinearity issues}

To check the issue of multicollinearity, the variance inflation factor (VIF) among constructs was 
Table 2

Reliability and Validity

\begin{tabular}{|c|c|c|c|c|c|c|c|c|}
\hline & $\begin{array}{c}\text { Cronbach's } \\
\text { Alpha }\end{array}$ & CR & AVE & BEO & FS & WFC & LS & PD \\
\hline BEO & 0.755 & 0.835 & 0.504 & $0.710^{\mathrm{a}}$ & & & & \\
\hline FS & 0.809 & 0.862 & 0.512 & 0.127 & $0.715^{\mathrm{a}}$ & & & \\
\hline WFC & 0.725 & 0.815 & 0.471 & 0.422 & -0.117 & $0.686^{a}$ & & \\
\hline LS & 0.685 & 0.826 & 0.613 & -0.018 & 0.451 & 0.026 & $0.783^{a}$ & \\
\hline PD & 0.775 & 0.838 & 0.425 & 0.083 & -0.418 & 0.272 & -0.191 & $0.652^{\mathrm{a}}$ \\
\hline
\end{tabular}

(CR - Composite Reliability, AVE - Average Variance Extracted). (BEO - Breach of Employer Obligations, FS - Family Satisfaction, WFC - Work Family Conflict, LS - Life Satisfaction, PD - Psychological Distress). ( ${ }^{a}$ Diagonal elements are square roots of the average variance extracted).

Table 3

Inner and Outer Variance Inflated Factors (VIF)

\begin{tabular}{|c|c|c|c|c|c|c|c|c|c|}
\hline \multicolumn{4}{|c|}{ Outer VIF } & \multicolumn{6}{|c|}{ Inner VIF } \\
\hline BEO1 & 1.421 & WF3 & 1.385 & & BEO & FS & WFC & LS & PD \\
\hline $\mathrm{BEO} 2$ & 1.646 & WF4 & 1.434 & BEO & & & 1 & & \\
\hline BEO3 & 1.399 & WF5 & 1.383 & FS & & & & & \\
\hline BEO4 & 1.341 & LS1 & 1.316 & WFC & & & & & 1 \\
\hline BEO5 & 1.33 & LS2 & 1.366 & LS & & & & & \\
\hline FS1 & 1.827 & LS3 & 1.318 & PD & & 1 & & 1 & \\
\hline FS10 & 1.523 & PD10 & 1.501 & & & & & & \\
\hline FS2 & 1.897 & PD3 & 1.356 & & & & & & \\
\hline FS3 & 1.345 & PD5 & 1.311 & & & & & & \\
\hline FS6 & 1.384 & PD6 & 1.382 & & & & & & \\
\hline FS9 & 1.463 & PD7 & 1.318 & & & & & & \\
\hline WF1 & 1.261 & PD8 & 1.3 & & & & & & \\
\hline WF2 & 1.215 & PD9 & 1.326 & & & & & & \\
\hline
\end{tabular}

(BEO - Breach of Employer Obligations, FS - Family Satisfaction, WFC - Work Family Conflict, LS - Life Satisfaction, PD - Psychological Distress). (Note: See Appendix 1 for detailed items)

examined. The outer VIF values show the collinearity among the items in constructs and inner VIF shows the collinearity among the latent variable [72] suggested that the value of VIF should be less than five. Table 3 shows the collinearity statistics of all the constructs (inner VIF) and all the values of VIF are less than five. Similarly, for the outer VIF refer to Table 3. This implies that no collinearity problems are existing among the constructs.

\subsection{Common method bias and non-response bias}

In PLS-SEM context, the common method bias (CMB) occurs because of the errors in the measurement model rather than the cause and effect in the structural model [73]. For this study, we collected the data through a structured questionnaire and thus, it was necessary to check whether the data is free from common method bias. We conducted Harman's single factor test, and a single factor is accounted for 28.77 per cent of the variance. Hence, the data was free from common method bias [74]. Further, non-response bias is found as no difference was seen between the early and late respondents in the survey [75].

\subsection{Structural model}

After checking the compatibility of the measurement model, the structural model (refer to Fig. 2) is analyzed to verify the proposed hypothesis and predict the model. In PLS-SEM, the model can be predicted by estimating $\mathrm{R}^{2}$ and $\mathrm{Q}^{2}$. $\mathrm{R}^{2}$ is accurately 


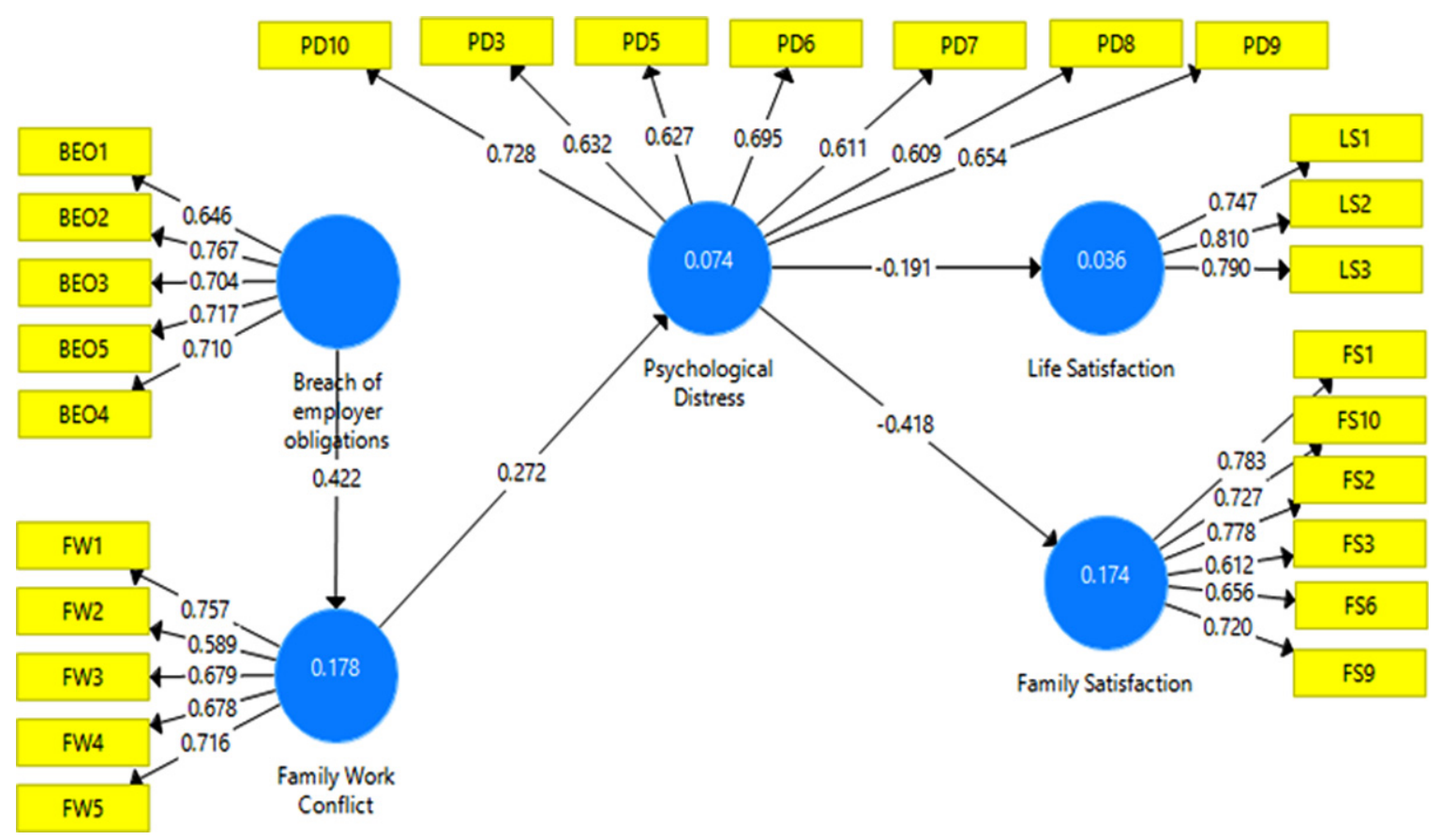

Fig. 2. Structural Model.

Table 4

$\mathrm{R}^{2}, \mathrm{~F}^{2}$ and $\mathrm{Q}^{2}$

\begin{tabular}{|c|c|c|c|c|c|c|c|c|c|}
\hline \multicolumn{2}{|c|}{$\mathrm{R}^{2}$} & \multicolumn{6}{|c|}{$\mathrm{F}^{2}$} & \multicolumn{2}{|c|}{$\mathrm{Q}^{2}$} \\
\hline & & & BEO & FS & FWC & LS & PD & & \\
\hline FS & 0.174 & BEO & & & 0.216 & & & BEO & - \\
\hline FWC & 0.178 & FS & & & & & 0.08 & FS & 0.085 \\
\hline LS & 0.036 & FWC & & & & & & FWC & 0.073 \\
\hline PD & 0.074 & LS & & & & & & LS & 0.028 \\
\hline & & PD & & 0.211 & & 0.038 & & PD & 0.03 \\
\hline
\end{tabular}

(BEO - Breach of Employer Obligations, FS - Family Satisfaction, WFC - Work Family Conflict, LS - Life Satisfaction, PD - Psychological Distress)

predicting the variance explained by the construct, and $\mathrm{Q}^{2}$ proposes predictive relevance by using the sample reusing method where part of the data matrix is being omitted, and results are used to predict the omitted part. [72] stated that the higher the $\mathrm{R}^{2}$ (ranging from 0 to 1 ), the higher the predictive accuracy would be. The $\mathrm{R}^{2}$ of the exogenous variables work family conflict, psychological distress, life satisfaction and family satisfaction were $0.178,0.074,0.036$, 0.174 , respectively. All the values were higher than 10 per cent (except psychological distress and life satisfaction), as recommended by [76] and considered to be good, as suggested by [72]. Hence, it signifies a robust explanatory power of the model (Table 4).
To verify the predictive orientation of the model, the Stone-Geisser's $Q^{2}$ is used [72]. The assessment of $\mathrm{Q}^{2}$ proposes predictive relevance by using sample reusing method where part of the data matrix is being omitted, and results are used to predict the omitted part. Hence, this blindfolding technique assesses the model's predictive accuracy. The higher value of $\mathrm{Q}^{2}$ implies less deviation in estimated and original values. Hence, $Q^{2}$ should be more significant than 0 (refer to Table 4). [72] recommended that the values of $\mathrm{Q}^{2}$, that is, the predictive indices 0.02 , 0.15 , and 0.35 , are regarded as small, medium and large effects, respectively. Here, $Q^{2}$ value of the family satisfaction, family-work conflict, life satisfaction 


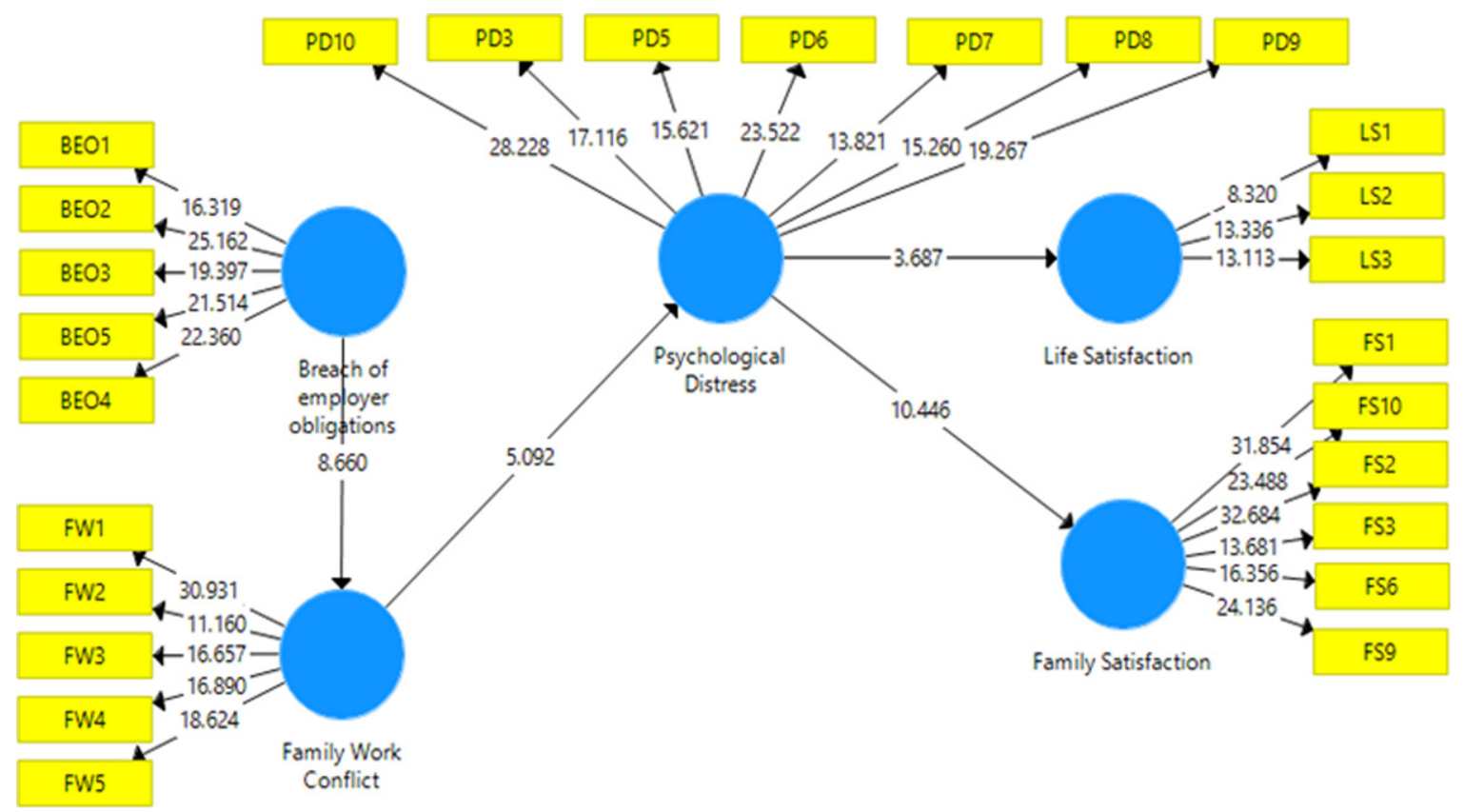

Fig. 3. Bootstrapping Results.

and psychological distress were $0.085,0.073,0.028$ and 0.03 respectively; it infers the medium effect of in predicting variance in family-work conflict, psychological distress and family satisfaction and life satisfaction during COVID-19 unlock phase. $\mathrm{F}^{2}$ is calculated to estimate the effect size. [77] suggested that the values of $\mathrm{f}^{2}$ as $0.02,0.15$ and 0.35 are considered to have small, medium and large effects, respectively. Table 4 reflects the $\mathrm{f}^{2}$ effect size. Familywork conflict and family satisfaction were having 0.216 and 0.211 respectively, i.e. medium effect size. Life satisfaction and psychological distress were having 0.03 and 0.08 , i.e. small effect size (Table 4).

To verify the postulated hypothesis and check the relationship among the constructs, the path coefficients are calculated by using the bootstrapping, $\mathrm{t}$ values and $P$ values. From Table 4 , it is revealed that the bootstrapping results of resampling technique (5,000 subsamples) examine the influence of breach of employer obligations on family-work conflict; family-work conflict on psychological distress; and psychological distress on family satisfaction and life satisfaction. Table 5 depicts the path coefficients, $\mathrm{t}$ values and $P$ values of the proposed hypothesis. H1 postulating a positive relationship between breach of employer obligations and family-work conflict is significant as $\beta=0.422$ and $\mathrm{t}$ value $=8.66$, $P$-value $<0.05$. Hence, it supports H1. It implies that during COVID-19 if employees' expectations were not fulfilled, then it causes family-work conflict. Likewise, $\mathrm{H} 2$ conjectured that family-work conflict positively impacts psychological distress, and it is supported as $\beta=0.272$ and $\mathrm{t}$ value $=5.09$, $P$-value $<0.05$. This means that as the familywork conflict increases psychological distress also increases. Similarly, H3, H3a, and H3b postulated that psychological distress was negatively impacting life satisfaction $(\beta=-0.191$ and $t$ value $=3.67$, $P<0.05)$, and family satisfaction $(\beta=-0.418$ and $\mathrm{t}$ value $=10.44, P<0.05)$ respectively.

\section{Discussion}

Anchored in SET, COR and SIP theory, findings of the study suggested that breach of employer obligations indirectly lead to reduced well-being through family-work conflict and psychological distress. The results are consistent with the past studies where a breach of PC lead to the negative impact on the job attitudes [78-81]. The relationship between breach of employer obligations and family-work conflict is not given much attention in the past studies, but it is necessary to study in the pandemic situation where jobs are having a high impact on their workfamily balance. According to [82] balancing work 
Table 5

Path Coefficients

\begin{tabular}{lccccc}
\hline & $\begin{array}{c}\text { Original } \\
\text { Sample (O) }\end{array}$ & $\begin{array}{c}\text { Sample } \\
\text { Mean (M) }\end{array}$ & $\begin{array}{c}\text { Standard } \\
\text { Deviation (STDEV) }\end{array}$ & $\begin{array}{c}\text { T Statistics } \\
(\text { O/STDEV) }\end{array}$ & $P$ Values \\
\hline BEO -> WFC & 0.422 & 0.436 & 0.049 & 8.66 & 0 \\
WFC - > PD & 0.272 & 0.276 & 0.054 & 5.092 & 0 \\
PD -> FS & -0.418 & -0.43 & 0.04 & 10.446 & 0 \\
PD -> LS & -0.191 & -0.205 & 0.052 & 3.687 & 0 \\
\hline
\end{tabular}

(BEO - Breach of Employer Obligations, FS - Family Satisfaction, WFC - Work Family Conflict, LS - Life Satisfaction, PD - Psychological Distress).

and life is one of the expectations of the employees and if that is not fulfilled, then it leads to negative consequences [83]. In the past studies, it has been argued that employers play a vital role in reinforcing expectations about work and family $[84,85]$. In the era of uncertainty, when employees perceive a breach of expectations, it leads to the family-work conflict $[14,86]$. Empirical studies also suggested that conflict arising from work-family interface negatively impacted on psychological distress [87, 88]. [89] explored that family-work conflict significantly related to stress and satisfaction among correctional officers of Southern State. [90] surveyed the work experience of Australian construction professional and found that stress is a result of the work-family interface and job pressure. The current study also proves that the relationship between psychological distress and well-being was negative. This clearly indicated that lower the psychological distress, higher the well-being. SIP theory suggests that during the pandemic situation, employees are receiving information from newspapers, social media and other online sources and process this information as per their understanding, which also generates stress and has an effect on their well-being. Stress and wellbeing are closely connected [37], and the results were in line with past studies where there was a negative relationship between psychological distress and well-being. [44, 45]. For instance, [59] also proved that lower the psychological distress has contributed to higher well-being among Australian students. In contrast, [91] have found in the meta-analytic study that there was an inverse relationship between psychological distress and well-being among young adults. Based on the conservation of resource theory, many studies have given similar outcomes that psychological distress affects the well-being (life satisfaction and family satisfaction) $[30,87]$.

\subsection{Theoretical implications}

The study is drawn from multiple theories such as SET, COR and SIP. [92] suggested that in the Asian context, the psychological contract is explained by single theory only such as social exchange theory. [93-95] argued that social exchange theory is a transactional model of understanding the employeremployee relationship. Thus, multi-theoretical lens aid in explaining the employer-employee relationship and outcomes of psychological contract in a better manner. In the era of social distancing, social information processing theory suggested that an individual's behaviour is an outcome of the observation of the social environment and information that he/she received from surroundings. In the COVID-19 pandemic situation, the individual has limitations on the social information, and according to COR theory, we argued that employee experience distress at work when employer/manager is unable to provide appropriate resources to perform the task [20]. COR model [21] indicated that people do their best to keep valued matters, called resources, in their lives [96] (including meeting their familial obligations). It also emphasized that occurrence of resource loss creates higher importance of resource gain as it provides emotional respite and increases an individual's ability to sustain goal pursuit [96]. Thus, the employees try to emotionally and cognitively attach to their jobs and try to access and exploit more resources. This leads employees to perceive that they can handle psychological distress which result in decreased life and family satisfaction. The findings of the study indicated that when employees' expectations are not met, it leads to family-work conflict. This conflict generates stress, and it affects negatively on well-being. Finally, the study was done in the developing country i.e. India during the COVID-19 pandemic situation. This is an additional advantage in terms of bringing 
evidence and support for the proposed model. Therefore, the importance of the most recent models during the pandemic and should be given much attention.

\subsection{Practical implications}

The study has some practical nuances. Well-being is an integral part of an individual's health and hence organization need to find a way of retaining the degree of vigor and ardor that people bring to work, especially as people work with minimal resources. [97] explicitly explained, human resources management is responsible for establishing as well as upholding the psychological contract between organization/employer and their employees. In other words, the employer should indicate what organization expects from its employees and what employees expect in return from the organization in this pandemic era. An organization should keep in mind that when employees suffer from an inability to balance work and family, they contemplate the reasons for failure and tend to blame the domain responsible for conflict and associated undesirable outcomes [98]. Once a breach of employer obligation arises, employees enter a sense-making process that determines their responses [99], which preventing them from meeting their home needs, ultimately decreasing their well-being. If anything is promised, then it must be real and there should be an attempt of fulfilling it. If the expectations are fulfilled then employee feels confident about the time spent and efforts made for the task completion, which creates the positive exchange relationship between both the parties [100]. HR managers and line managers should be aware that they need to assist their employees in fulfilling their legitimate demands because our finding has shown that stress negatively impacted their family satisfaction and life satisfaction. Therefore, the organizations should not only encourage the employees by meeting their expectations but also support them by providing adequate resources. When the employees perceive a breach of obligations, it has an adverse impact on family life, which creates conflict between familywork life. In the current situation, supervisors and managers must support their subordinates in an accurate and timely manner and should guide them to handle the job responsibility during this pandemic. This support and feedback amplify members' confidence in dealing with tasks and create a positive environment [101].

\subsection{Limitations and future research direction}

This study has several limitations that need to be addressed in further studies. First, the study was conducted during the COVID-19 pandemic situation. Hence, the results obtained summarizing the respondents' status of mind during pandemic situations only. Secondly, the study has considered the only breach of employer obligations as antecedents of outcome variables such as family-work conflict, psychological distress and well-being. In future breach of employee, obligations can be taken into consideration to validate the results. Thirdly, there are many factors which affect the well-being and this study has included only two factors, namely life satisfaction and family satisfaction. In future, other industry-specific variables can be taken to understand overall well-being. Fourth, the study has taken into consideration outcome or dependent variable, i.e. well-being. In future studies, other outcome variables can be taken into consideration which can be affected by psychological distress. Fifth, the researchers have adopted a cross-sectional design. Breach of employer obligations may affect the long term domains of behaviour, whereas stress can be short term or time or situationspecific. In future, the longitudinal study could make it possible to explore different time effects on well-being, and it can make results stronger and justifiable.

\section{Conclusion}

This study has explored possible pathways between the vital constructs of organizational behaviour, namely: breach of employer obligations, family-work conflict, psychological distress and well-being. These constructs are vital for the employment relationship. The results indicate that in order to retain well-being and reduce family-work conflict, organizations should strive to fulfill employees' PC and ensure that this is done in a fair manner. Psychological distress is one of the constructs which should be minimized to get positive outcomes at the workplace. Thus, the scholars in the field need to continue refining and defining our understanding of how these constructs and its inter-relationship affect the organization, employees and employment relationship and also endow with the evidence which may help in framing strategies and policies for the productive, efficient and healthy employment relationship. 


\section{Acknowledgments}

The authors are really grateful to the reviewers and editor for their expert insights.

\section{Author contributions}

CONCEPTION: Anushree Karani

METHODOLOGY: Anushree Karani

DATA COLLECTION: Payal Trivedi

INTERPRETATION OR ANALYSIS OF DATA:

Payal Trivedi

PREPARATION OF THE MANUSCRIPT: Anushree Karani, Revati Deshpande and Payal Trivedi REVISION FOR IMPORTANT INTELLECTUAL CONTENT: Anushree Karani and Mitesh Jayswal SUPERVISION: Anushree Karani and Mitesh Jayswal

\section{Supplementary material}

The appendix is available in the electronic version of this article: https://dx.doi.org/10.3233/ HSM-211210.

\section{References}

[1] Conway N, Guest D, Trenberth L. Testing the differential effects of changes in psychological contract breach and fulfillment. J Vocat Behav. 2011;79(1):267-76.

[2] Argyris C. Understanding Organisational Behaviour. London, Tavistock Publications. 1960.

[3] Taylor MS, Tekleab AG. Taking stock of psychological contract research: Assessing progress, addressing troublesome issues, and setting research priorities. Employ Relatsh Examining Psychol Context Perspect. 2004; 253:283.

[4] Rousseau DM. Psychological and implied contracts in organizations. Empl Responsib rights J. 1989;2(2):121-39.

[5] PTI. COVID-19 pandemic worse than 2008-09 financial crisis: IMF. 2020 Apr 15; Available from: https://economic times.indiatimes.com/news/international/world-news/ covid-19-pandemic-worse-than-2008-09-financial-crisisimf/articleshow/75161296.cms?from $=\mathrm{mdr}$

[6] TOI. With pay cuts and job loss, Coronavirus pandemic might set back your career by 3 years or more! 2020 May 7; Available from: https://timesofindia.indiatimes.com/lifestyle/relationships/love-sex/with-pay-cuts-and-job-losscoronavirus-pandemic-might-set-back-your-career-by-3years-or-more/photostory/75596488.cms

[7] The Australian Psychological Society. Maintaining employee engagement during COVID-19 [Internet]. The Australian Psychological Society Limited. 2020 [cited
2020 Aug 17]. pp. 3. Available from: https://www.psycho logy.org.au/getmedia/5c7bd7ac-7229-41fa-867b-68a265 fb237f/APS-COP-IS-COVID-19-Employee-engage ment-P1.pdf

[8] Restubog SLD, Zagenczyk TJ, Bordia P, Tang RL. When employees behave badly: The roles of contract importance and workplace familism in predicting negative reactions to psychological contract breach. J Appl Soc Psychol. 2013;43(3):673-86.

[9] Conway N, Briner RB. A daily diary study of affective responses to psychological contract breach and exceeded promises. J Organ Behav Int J Ind Occup Organ Psychol Behav. 2002;23(3):287-302.

[10] Rigotti T. Enough is enough? Threshold models for the relationship between psychological contract breach and job-related attitudes. Eur J Work Organ Psychol. 2009; 18(4):442-63.

[11] Priesemuth M, Taylor RM. The more I want, the less I have left to give: The moderating role of psychological entitlement on the relationship between psychological contract violation, depressive mood states, and citizenship behavior. J Organ Behav. 2016;37(7):967-82.

[12] Andrews FM, Withey SB. Social Indicators of Well-Being. PlenumPress, New York. 1976.

[13] Kaya B, Karatepe OM. Does servant leadership better explain work engagement, career satisfaction and adaptive performance than authentic leadership? Int J Contemp Hosp Manag. 2020;32(6):2075-2095. DOI: 10.1108/IJCHM-05-2019-0438

[14] Hill RT, Morganson VJ, Matthews RA, Atkinson TP. LMX, breach perceptions, work-family conflict, and wellbeing: A mediational model. J Psychol. 2016;150(1): 132-49.

[15] Cooper CL, Cartwright S. An intervention strategy for workplace stress. J Psychosom Res. 1997;43(1):7-16.

[16] Blau PM. Social exchange theory. Retrieved Sept. 1964; 3(2007):62.

[17] Salancik GR, Pfeffer J. A social information processing approach to job attitudes and task design. Adm Sci Q. 1978;224-53.

[18] Gouldner AW. The norm of reciprocity: A preliminary statement. Am Sociol Rev. 1960;161-78.

[19] Perugini M, Gallucci M. Individual differences and social norms: The distinction between reciprocators and prosocials. Eur J Pers. 2001;15(S1):S19-35.

[20] Byrne A, Dionisi AM, Barling J, Akers A, Robertson J, Lys R, et al. The depleted leader: The influence of leaders' diminished psychological resources on leadership behaviors. Leadersh Q. 2014;25(2):344-57.

[21] Hobfoll SE, Shirom A. Stress and burnout in the workplace: Conservation of resources. Handb Organ Behav. 1993;1:41-61.

[22] Duran F, Bishopp D, Woodhams J. Relationships between psychological contract violation, stress and well-being in firefighters. Int J Work Heal Manag. 2019;

[23] Rousseau DM. Psychological and implied contracts in organizations. Empl Responsib Rights J. 1989;2(2): 121-39.

[24] Robinson SL, Kraatz MS, Rousseau DM. Changing obligations and the psychological contract: A longitudinal study. Acad Manag J. 1994;37(1):137-52. 
[25] Garcia PRJM, Bordia P, Restubog SLD, Caines V. Sleeping with a broken promise: The moderating role of generativity concerns in the relationship between psychological contract breach and insomnia among older workers. J Organ Behav. 2018;39(3):326-38.

[26] Restubog SLD, Scott KL, Zagenczyk TJ. When distress hits home: The role of contextual factors and psychological distress in predicting employees' responses to abusive supervision. J Appl Psychol. 2011;96(4):713.

[27] Arshad R. Psychological contract violation and turnover intention: do cultural values matter? J Manag Psychol. 2016;31(1):251-264. DOI: 10.1108/JMP-10-20130337

[28] Heffernan M, Rochford E. Psychological contract breach and turnover intention: The moderating effects of social status and local ties. Irish J Manag. 2017;36(2):99-115.

[29] Salin D, Notelaers G. The effect of exposure to bullying on turnover intentions: the role of perceived psychological contract violation and benevolent behaviour. Work Stress. 2017;31(4):355-74.

[30] Turner N, Hershcovis MS, Reich TC, Totterdell P. Workfamily interference, psychological distress, and workplace injuries. J Occup Organ Psychol. 2014;87(4):715-32.

[31] Smithson J, Lewis S. The Psychological Contract and Work-Family1. Organ Manag J. 2004;1(1):70-80.

[32] Kinnunen U, Feldt T, Geurts S, Pulkkinen L. Types of work-family interface: Well-being correlates of negative and positive spillover between work and family. Scand J Psychol. 2006;47(2):149-62.

[33] Frone MR, Yardley JK, Markel KS. Developing and testing an integrative model of the work-family interface. J Vocat Behav. 1997;50(2):145-67.

[34] Jansen NWH, Kant I, Kristensen TS, Nijhuis FJN. Antecedents and consequences of work-family conflict: A prospective cohort study. J Occup Environ Med. 2003; 45(5):479-91.

[35] Frone MR, Russell M, Barnes GM. Work-family conflict, gender, and health-related outcomes: A study of employed parents in two community samples. J Occup Health Psychol. 1996;1(1):57.

[36] Facey AD, Tallentire V, Selzer RM, Rotstein L. Understanding and reducing work-related psychological distress in interns: a systematic review. Intern Med J. 2015; 45(10):995-1004.

[37] Warr P. The measurement of well-being and other aspects of mental health. J Occup Psychol. 1990;63(3):193-210.

[38] Australian Safey and Compensation Council. Guidance on the principles of safe design for work. Canberra, Aust Author. 2006.

[39] Netemeyer RG, Brashear-Alejandro T, Boles JS. A crossnational model of job-related outcomes of work role and family role variables: A retail sales context. J Acad Mark Sci. 2004;32(1):49-60.

[40] Bedeian AG, Burke BG, Moffett RG. Outcomes of work-family conflict among married male and female professionals. J Manage. 1988;14(3):475-91.

[41] Maslach C, Jackson SE. The measurement of experienced burnout. J Organ Behav. 1981;2(2):99-113.

[42] Judge TA, Boudreau JW, Bretz RD. Job and life attitudes of male executives. J Appl Psychol. 1994;79(5):767.
[43] Sonnentag S. Dynamics of well-being. Annu Rev Organ Psychol Organ Behav. 2015;2(1):261-93.

[44] Schönfeld P, Brailovskaia J, Bieda A, Zhang XC, Margraf J. The effects of daily stress on positive and negative mental health: Mediation through self-efficacy. Int J Clin Heal Psychol. 2016;16(1):1-10.

[45] Thoits PA. Stress and health: Major findings and policy implications. J Health Soc Behav. 2010;51(1_suppl): S41-53.

[46] Hart PM. Predicting employee life satisfaction: A coherent model of personality, work, and nonwork experiences, and domain satisfactions. J Appl Psychol. 1999;84(4):564.

[47] Satici B, Gocet-Tekin E, Deniz ME, Satici SA. Adaptation of the Fear of COVID-19 Scale: Its association with psychological distress and life satisfaction in Turkey. Int $\mathbf{J}$ Ment Health Addict. 2021;19:1980-1988.

[48] Cammann CF, Jenkins MD, Klesh J. The Michigan Organizational Assessment Questionnaire. Unpubl Manuscript, Univ Michigan Ann Arbor. 1979.

[49] Carver MD, Jones WH. The family satisfaction scale. Soc Behav Personal an Int J. 1992;20(2):71-83.

[50] Michel JS, Kotrba LM, Mitchelson JK, Clark MA, Baltes BB. Antecedents of work-family conflict: A meta-analytic review. J Organ Behav. 2011;32(5):689-725.

[51] Ford MT, Heinen BA, Langkamer KL. Work and family satisfaction and conflict: a meta-analysis of cross-domain relations. J Appl Psychol. 2007;92(1):57.

[52] Karani A, Deshpande R, Jayswal M, Panda R. Work-life balance and psychological distress: A structural equation modeling approach. Hum Syst Manag. 2021;41(1):1-15.

[53] Karani A, Deshpande R, Mall S, Jayswal M. Testing the link between psychological contract, innovative behavior and multidimensional well-being during the COVID-19 pandemic. Int J Sociol Soc Policy. 2021; ahead of print.

[54] Dartey-Baah K, Quartey SH, Osafo GA. Examining occupational stress, job satisfaction and gender difference among bank tellers: evidence from Ghana. Int $\mathbf{J}$ Product Perform Manag. 2020;69(7):1437-1454. DOI: 10.1108/IJPPM-07-2019-0323

[55] Chummar S, Singh P, Ezzedeen SR. Exploring the differential impact of work passion on life satisfaction and job performance via the work-family interface. Pers Rev. 2019;48(5):1100-1119. DOI: 10.1108/PR-02-2017-0033

[56] Probst TM, Sinclair RR, Sears LE, Gailey NJ, Black KJ, Cheung JH. Economic stress and well-being: Does population health context matter? J Appl Psychol. 2018; 103(9):959.

[57] Bakker AB, Derks D. Positive occupational health psychology. Occup Heal Psychol. 2010;194-224.

[58] Deery S, Iverson R, Walsh J. Work relationships in telephone call centres: Understanding emotional exhaustion and employee withdrawal. J Manag Stud. 2002;39(4): 471-96.

[59] Bore M, Pittolo C, Kirby D, Dluzewska T, Marlin S. Predictors of psychological distress and well-being in a sample of Australian undergraduate students. High Educ Res Dev. 2016;35(5):869-80.

[60] Anderson AR, Fowers BJ. Lifestyle behaviors, psychological distress, and well-being: A daily diary study. Soc Sci Med. 2020;263:113263. 
[61] Rathi N, Barath M. Work-family conflict and job and family satisfaction: Moderating effect of social support among police personnel. Equal Divers Incl An Int J. 2013;32(4):438-454.

[62] Park R, Jang SJ. Family role overload's relationship with stress and satisfaction. J Manag Psychol. 2017;

[63] Robinson SL, Wolfe Morrison E. The development of psychological contract breach and violation: A longitudinal study. J Organ Behav. 2000;21(5):525-46.

[64] Netemeyer RG, Boles JS, McMurrian R. Development and validation of work-family conflict and family-work conflict scales. J Appl Psychol. 1996;81(4):400.

[65] Radloff L. Sex differences in depression. Sex Roles. 1975; 1(3):249-65.

[66] Zheng X, Zhu W, Zhao H, Zhang C. Employee well-being in organizations: Theoretical model, scale development, and cross-cultural validation. J Organ Behav. 2015;36(5): 621-44.

[67] Chang EC, Yi S, Liu J, Kamble S V, Zhang Y, Shi B, et al. Coping Behaviors as Predictors of Hedonic WellBeing in Asian Indians: Does Being Optimistic Still Make a Difference? J Happiness Stud. 2020;21(1):289-304.

[68] Diener ED, Emmons RA, Larsen RJ, Griffin S. The satisfaction with life scale. J Pers Assess. 1985;49(1):71-5.

[69] Hair JF, Ringle CM, Sarstedt M. PLS-SEM: Indeed a silver bullet. J Mark theory Pract. 2011;19(2):139-52.

[70] Nunnally JC. Psychometric Theory: 2d Ed. McGraw-Hill; 1978.

[71] Fornell C, Larcker DF. Structural equation models with unobservable variables and measurement error: Algebra and statistics. SAGE Publications: Los Angeles; 1981.

[72] Hair Jr JF, Sarstedt M, Ringle CM, Gudergan SP. Advanced issues in partial least squares structural equation modeling. Sage publications; 2017.

[73] Kock N. WarpPLS user manual: Version 6.0. ScriptWarp Syst Laredo, TX, USA. 2017.

[74] Podsakoff PM, MacKenzie SB, Lee J-Y, Podsakoff NP. Common method biases in behavioral research: a critical review of the literature and recommended remedies. J Appl Psychol. 2003;88(5):879.

[75] Armstrong JS, Overton TS. Estimating nonresponse bias in mail surveys. J Mark Res. 1977;14(3):396-402.

[76] Falk RF, Miller NB. A primer for soft modeling. University of Akron Press; 1992.

[77] Sarstedt M, Ringle CM, Hair JF. Partial least squares structural equation modeling. Handb Mark Res. 2017;26:1-40.

[78] Li JJ, Wong IA, Kim WG. Effects of psychological contract breach on attitudes and performance: The moderating role of competitive climate. Int J Hosp Manag. 2016;55: 1-10.

[79] Abela F, Debono M. The relationship between psychological contract breach and job-related attitudes within a manufacturing plant. SAGE Open. 2019;9(1):215824 4018822179.

[80] Bal PM, Kooij D. The relations between work centrality, psychological contracts, and job attitudes: The influence of age. Eur J Work Organ Psychol. 2011;20(4):497-523.

[81] Bal PM, De Lange AH, Jansen PGW, Van Der Velde MEG. Psychological contract breach and job attitudes: A meta-analysis of age as a moderator. J Vocat Behav. 2008; 72(1):143-58

[82] Freese C, Schalk R. How to measure the psychological contract? A critical criteria-based review of measures. South African J Psychol. 2008;38(2):269-86.

[83] Kraak JM, Russo M, Jiménez A. Work-life balance psychological contract perceptions for older workers. Pers Rev. 2018;47(6):1194-1210. DOI: 10.1108/PR-10-20170300

[84] Allen MW, Armstrong DJ, Reid MF, Riemenschneider CK. Factors impacting the perceived organizational support of IT employees. Inf Manag. 2008;45(8): 556-63.

[85] Taylor BL, DelCampo RG, Blancero DM. Work-family conflict/facilitation and the role of workplace supports for US Hispanic professionals. J Organ Behav. 2009; 30(5):643-64.

[86] Reimann M, Pausch S, Diewald M. Work-Family Conflict in Germany: Psychological Contracts as Part of Employment Relationships in Work-Family Research. Psychosociological Issues Hum Resour Manag. 2017;5(2): 127-53.

[87] Abubakar AM. Linking work-family interference, workplace incivility, gender and psychological distress. J Manag Dev. 2018;37(3):226-242. DOI: 10.1108/JMD-062017-0207

[88] Houlfort N, Philippe FL, Bourdeau S, Leduc C. A comprehensive understanding of the relationships between passion for work and work-family conflict and the consequences for psychological distress. Int J Stress Manag. 2018;25(4):313.

[89] Armstrong GS, Atkin-Plunk CA, Wells J. The relationship between work-family conflict, correctional officer job stress, and job satisfaction. Crim Justice Behav. 2015; 42(10): 1066-82.

[90] Bowen P, Govender R, Edwards P, Cattell K. The role of after-hours, work-related contact in workto-family conflict and sleep problems experienced by construction professionals. Association of Researchers in Construction Management (ARCOM); 2017.

[91] Marino C, Gini G, Vieno A, Spada MM. The associations between problematic Facebook use, psychological distress and well-being among adolescents and young adults: A systematic review and meta-analysis. J Affect Disord. 2018;226:274-81

[92] Kutaula S, Gillani A, Budhwar PS. An analysis of employment relationships in Asia using psychological contract theory: A review and research agenda. Hum Resour Manag Rev. 2019;100707.

[93] Zagenczyk TJ, Gibney R, Few WT, Scott KL. Psychological contracts and organizational identification: The mediating effect of perceived organizational support. J Labor Res. 2011;32(3):254-81.

[94] Tekleab AG, Laulié L, De Vos A, De Jong JP, CoyleShapiro JAM. Contextualizing psychological contracts research: a multi-sample study of shared individual psychological contract fulfilment. Eur J Work Organ Psychol. 2019;1-15.

[95] Choi W, Kim SL, Yun S. A social exchange perspective of abusive supervision and knowledge sharing: Investigating the moderating effects of psychological contract 
fulfillment and self-enhancement motive. J Bus Psychol. 2019;34(3):305-19.

[96] Hobfoll SE. Social and psychological resources and adaptation. Rev Gen Psychol. 2002;6(4):307-24.

[97] Sparrow J. Knowledge in organizations: Access to thinking at work. J Knowl Manag. 1998;2(1):84.

[98] Scott SG, Bruce RA. Determinants of innovative behavior: A path model of individual innovation in the workplace. Acad Manag J. 1994;37(3):580-607.

[99] Rosen CC, Chang C-H, Johnson RE, Levy PE. Perceptions of the organizational context and psychological contract breach: Assessing competing perspectives. Organ Behav Hum Decis Process. 2009;108(2):202-17.

[100] Cheung MFY, Chiu WCK. Effects of psychological contract fulfillment, perceived organizational support, leader-member exchange, and work outcomes: A test of a mediating model. Hong Kong Polytech Univ Work Pap. 2005.

[101] Xanthopoulou D, Baker AB, Heuven E, Demerouti E, Schaufeli WB. Working in the sky: A diary study on work engagement among flight attendants. J Occup Health Psychol. 2008;13(4):345.
[102] Westrupp EM, Strazdins L, Martin A, Cooklin A, Zubrick SR, Nicholson JM. Maternal work-family conflict and psychological distress: reciprocal relationships over 8 years. Journal of Marriage and Family. 2016;78(1): 107-26.

[103] Bilodeau J, Marchand A, Demers A. Work, family, workfamily conflict and psychological distress: A revisited look at the gendered vulnerability pathways. Stress and Health. 2020;36(1):75-87.

[104] Aazami S, Shamsuddin K, Akmal S. Examining behavioural coping strategies as mediators between workfamily conflict and psychological distress. The Scientific World Journal. 2015. DOI: 10.1155/2015/343075

[105] Abdelmoteleb SA. The interrelationships among job satisfaction, work-home interference and psychological contract breach. German Journal of Human Resource Management. 2019;33(1):32-55. 